\title{
Physio-chemical evaluation and Co-combustion efficiency of different biomass waste fractions with indigenous coal blends for utilization as alternative fuel
}

\author{
Majeed A. ${ }^{1}$, Kanwal S. ${ }^{2 *}$, Batool S.A. ${ }^{3}$, Chaudhry M.N. ${ }^{4}$, Zeb H. ${ }^{2}$, Abbasi G.H. ${ }^{1}$, Malik Z. ${ }^{5}$ and Munir A. ${ }^{1}$ \\ ${ }_{1}^{1}$ Department of Environmental Science, Faculty of Agriculture and Environment, The Islamia University of Bahawalpur, Pakistan \\ ${ }^{2}$ Institute of Energy and Environmental Engineering, University of the Punjab, Pakistan \\ ${ }^{3}$ Remote Sensing, GIS and Climate Change Research Lab (National Center of GIS and Space Applications), Department of Space \\ Sciences, University of the Punjab, Pakistan \\ ${ }^{4}$ Department of Environmental Science and Policy, Lahore School of Economics, Pakistan \\ ${ }^{5}$ Department of Soil Science, Faculty of Agriculture and Environment, The Islamia University of Bahawalpur, Pakistan \\ Received: 05/12/2020, Accepted: 10/01/2022, Available online: 22/01/2022 \\ *to whom all correspondence should be addressed: e-mail: sumaira.ieee@pu.edu.pk \\ https://doi.org/10.30955/gnj.003479
}

\section{Graphical abstract}

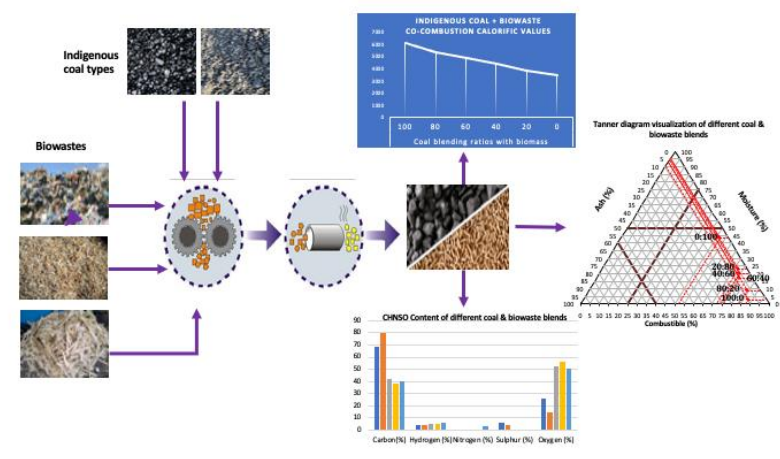

\section{Abstract}

Severe energy crisis and vilest economic conditions in Pakistan demand the country's energy portfolio to be revised with increased reliance on indigenous energy resources. The perspective of utilization of abundantly available biomass waste fractions as a fuel alone and their co-combustion with two different indigenous coal varieties has been emphasized in this study. Coal samples were blended with the organic fraction of municipal solid waste, rice husk and sugarcane bagasse waste fractions in varying ratios of $20 \%, 40 \%, 60 \%$ and $80 \%$ and the resulting variation in their fuel characteristics and co-combustion efficiency was determined. The execution is a basis to assess the assumption that co-combustion in appropriate proportions can arrange a solution for the massive amounts of produced organic waste and cut dependency on imported energy sources. The tanner diagram visualization for the assessment of proposed blends suggest that the blending samples exhibit an increase in moisture and combustible content while some decrease in ash content and calorific values with increased biomass ratios. Within the assortment of conducted trials, khaushab coal and rice husk in various proportions evidenced to be the best arrangement for fuel consumption based on energetic optimization. The overall results of studies inferred that both coal and biomass fuels alone and their co-firing can sustain self-combustion and subsequently arrange for finding area-based solutions related to various energy operations.

Keywords: Waste to energy, Co-combustion, biomass waste fractions, energetic assessment, tanner diagram.

\section{Introduction}

Since waste management hierarchical approach obligates to follow an explicit waste management scheme [DellBorghi, 2009; Seadon, 2006] Integrated Waste Management (IWM) is a contemporary approach that induces to determine the locally appropriate waste management option(s) in any preferred order [Seadon, 2006; Eriksson et al., 2014]. The most frequently used approach for the treatment of agricultural waste in most developing countries is composting. The organic matter is subjected to aerobic or anaerobic decomposition using microbes to produce compost, an effective soil conditioner [Ngoc and Schnitzer, 2009] Another familiar technique for biomass decomposition is anaerobic digestion that results in the generation of biogas rich in methane $(60 \%)$ together with hydrogen and carbon dioxide [Abbasi et al., 2012; Amjid et al., 2011]. Anaerobic digestion potential of Pakistan organic waste is abundant with an estimate of 12-16 million $\mathrm{m} 3 /$ day however the efforts to undertake this solution on a sizeable scale have met only limited success with over 5357 small plants operating in the rural area of the country [Amjid et al., 2011; ADB, 2008]. The use of lignocellulosic biomass for ethanol production is another effective technique operating around the world. The fermentation process involves the hydrolysis of sugar to produce fuel through 
microbial activity [Mussatto et al., 2010]. Modern waste management systems cannot function without the use of thermal processes. Various available waste-to-energy techniques range from traditional ones (incineration and RDF incineration) with direct energy recovery to some modern thermo-conversion systems including liquefaction, trans-esterification, bioelectrochemical systems (BES), gasification, and pyrolysis leading to secondary fuels [Fruergaard and Astrup, 2011; Brunner and Rechberger, 2015]. Among these options pyrolysis and gasification are relatively well established. Pyrolysis takes place at a temperature of $400 \mathrm{C}$ and above in absence of oxygen, leading to the production of bio-oil, biochar, and fuel gas [Li et al., 2004]. While gasification requires much elevated temperature (700C) and the presence of oxygen to decompose biomass into the gaseous form [Kumar et al., 2009]. Another emerging practice to engage the energy value of waste fractions in a sustainable way implicates its co-combustion with auxiliary fuel in power plants or RDF plants to generate energy [Sahu et al., 2014; Williams et al., 2001]. The technology choice is influenced by the waste composition and geographic scope while potential economic, social, environmental, and energetic feasibility is also among decisive parameters.

Coal has long been the predominant source of energy for electricity production with an estimated contribution of $40.6 \%$ in the world's energy (Schiffer, 2016). Prompted by renewable portfolio standards, impending carbon legislation and shifting public apprehensions about the environment, the recent concerns are how to lower emissions and incorporate more renewable energy into the electricity generation mix. However, for now such concerns are bound to developed countries with stabilized energy consumption, the developing countries are still striving to even out their increasing demands for electricity. Some literature suggests that developing economies are increasing the coal dependency and more likely to follow the trend in coming years (IEA, 2019; Malkani, 2012; Schiffer, 2016; Sebi, 2019; Varadhan, 2019). To emphasize the conversion of power plants from coal-fired to co-fired by adding a percentage of sorted waste fraction to the fuel mix is assumed to optimize the treatment and management of waste streams in an effective and environmentally conscious manner. The strategic approach of exploiting the energy content through co-combustion is valuable as it effectively utilizes the energy content of waste leading to a reduction in fossil fuel consumption, reduced sulphur and mercury content, reduction in land requirement for disposal, job creation and preservation of environmental quality, (Abbasi et al., 2012; Dong et al., 2014; Fantin et al., 2015; Kondusamy and Kalamdhad, 2014; Kothari et al., 2014).

Owing to the demographic growth, rapid urbanization, rapidly changing lifestyles and consumption patterns, the problem of energy crisis and environmental degradation have become acute in Pakistan. Pakistan is facing an energy crisis with a supply and demand gap of up to 4,500-5,500 MW that demands the very basis of the country's energy policy to be revised (Asif, 2009; Rauf et al., 2015; Safeer and Fatima, 2019). The overdependency on imported fossil fuel led to energy insecurity and increased circular debt. The crisis has not only affected the household, but the industrial sector is also challenged with an economic crunch of almost 157 billion rupees while 400,000 employees were forced to quit their jobs (Yasmeen and Sharif, 2014). The expensive energy generation also puts economic burden on consumers. The minimum cost of one electrical unit is 10 Rs. for household while almost 25 Rs. for industrial sector. With huge funds allocation and several energy projects under implementation, the Government is focused towards increasing the energy potential of the country. Hence, to meet up the targets, the need is to invest for sustainable options in local context. The prevailing energy crisis complemented by environmental degradation demands a need to switch from expensive resources to increase reliance on indigenous energy resources along with the envision to incorporate the potential waste-to-energy generation alternative, particularly those utilizing sorted fractions such as organic waste and refuse derived fuel in the formulation of national energy policies.

Coal is an economically viable and a long-term solution to balance the demand and supply chain of electricity in the country with up to 186 billion tons coal deposits (Malkani, 2012). Pakistan consumes about 18 million tons of coal each year; the share of indigenous coal is about 4.3 million tons, while the balance has to be imported due to relatively lower calorific value of indigenous coal (GOP, 2018). Fifty-five thousand $(55,000)$ tons of municipal solid waste produced daily in congruence with ineffective solid waste management system distresses the environment at the national level (Hoi-Seong and Kwang-Yim, 2007). Since Pakistan is an agricultural country; many biomass waste resources are available for co-generation, an abundant potential lies in the sugar cane and rice husk industries. Rice is the second largest staple food crop of Pakistan, during the year 2017-18, almost 2.8 million hectares of land cultivated with rice with an estimated yield of 7.44 million tons. While sugar cane was cultivated at 1.31million-hectare area to produce almost 81.1 million tons of crop (GOP, 2018). Presently a huge amount of crop residues are being generated with a residue to crop ratio (RCR) of 0.25 for rice husk and 0.26 for sugarcane bagasse (Kojakovic and Maltsoglou, 2014). These quantities, if effectively collected may constitute a valuable source of energy.

Since Pakistan is an agricultural country with over 26,280,000 ha' land under cultivation [29], massive agricultural residues are generated as a by-product from the processing and harvesting of crops. The burning of crop residues is an old and usual practice in the rural community of Pakistan. Most of the Biomass feedstock is directly utilized in stoves and brick kilns [30]. Stubble burning is also a common sight that adds significant pollution loads to the environment. Such enormous potential demands to assess assorted environmentally friendly options to determine the most suitable and 
implementable area-appropriate scheme(s). This study aims to investigate the fuel characteristics of indigenous coal and different biomass waste fractions, while the cocombustion efficiency of indigenous coal with different biomass waste fractions, including the organic fraction of municipal solid waste, rice husk and sugarcane baggasse are also studied. The two indigenous types of coal i-e Chamalang coal and Khushab coal were combusted alone and blended with a series of biomass waste fraction in different proportions. A triangular plot known as Tanner diagram was used to make a rapid evaluation of tested fractions for energy related operations (Montgomery, 2005). The idea of co-combustion of coal and organic waste blends is based on energetic and economic optimization. The execution is a requisite to assess the assumption that making a blend of indigenous coal with biomass waste fraction in an appropriate proportion can arrange for solutions related to energy and economic concerns leading to a solution for the massive amounts of produced organic waste and increased reliance on indigenous coal.

\section{Materials and methods}

A number of experiments were carried out to evaluate the physical and chemical characteristics, calorific values, carbon and sulfur contents that ultimately affect the combustion efficiency and economic feasibility of different settings under consideration.

\subsection{Sample preparation}

Several components collected for the study include indigenous coal samples, organic fraction of municipal waste, rice husk and sugarcane baggasse. The sugarcae baggasse and rise husk samples were taken from local industries, while the MSW organic fraction was separated from the solid waste collected from Allama Iqbal town, Lahore. Two different indigenous coal varieties, namely Chamalang coal and Khaushab coal, named based on the places of their origin were also brought for analysis. Sampling was carried out according to (ASTM-D197-87 2007). All these fractions were prepared for further analysis through air drying, grinding and blending of the components at appropriate ratios. Air drying was carried out in ovens at ambient $+15 \mathrm{C}$ with hot air passing through the samples. Air dry loss (ADL) was also determined at this stage. The grinding was carried out using disc mills and the samples were prepared at 250 micrometer particle sizes. The Coal samples and biomass fractions were tested alone for various parameters and coal samples were blended with each of the biomass waste fraction in varying ratios of $20 \%, 40 \%, 60 \%$ and $80 \%$ and the resulting variation in their characteristics were determined.

\subsubsection{Proximate analysis}

For the determination of moisture content, volatile matter, ash and fixed carbon of the fractions under study an automatic, software controlled Thermogravimetric Analyzer (TGA 701) was used. In a standard crucible, one gram of sample (72 mesh size) was placed inside the furnace at $105 \pm 5 \mathrm{C}$ for one hour for moisture content determination. When the weight loss reached equilibrium, the samples were subjected for the determination of volatile matter under inert atmosphere (nitrogen atmosphere) for a period of 7 minutes at $950^{\circ} \mathrm{C}$. The sample is then subjected for ash determination under oxidative atmosphere at $750^{\circ} \mathrm{C}$ for a period of two hours. Fixed carbon is the residue after removal of volatile matter in the combustion process; it was calculated using the following formula

\section{Fixed Carbon = $100-$ (Moisture +Volatile matter + Ash)}

\subsubsection{Determination of Carbon, Hydrogen, Nitrogen, Sulphur and Oxygen (CHNSO) content}

The Carbon, hydrogen, nitrogen, sulphur contents of indigenous coal, municipal waste, rice husk and sugarcane bagasse samples were determined by using FLASH 2000 analyzer functions in accordance to ASTM D-5291. The FLASH 2000 analyzer functions according to the dynamic flash combustion of the sample. Samples were weighed into a tin capsule and introduced in the combustion reactor via the thermo scientific MAS 200R autosampler. The resultant gases after the combustion are taken by helium flow to a layer filled with copper, then swept through the GC column that split the combustion gases and eventually detected by a thermal conductivity detector (TCD). Oxygen (O) content was determined through an indirect calculation with respect to measured elements (CHNS) using equation 1

\section{$\mathrm{O} \%=100-\mathrm{C} \%-\mathrm{H} \%-\mathrm{N} \%-\mathrm{S} \%-\mathrm{Ash}$}

\subsubsection{Calorific value determination}

The calorific value indicates the amount of heat that is released when the coal is burned. The gross calorific value of coal and biomass fractions was determined using an automatic, software-controlled bomb calorimeter specifically designed to measure calorific value of any liquid or solid fuel samples (ASTM-E711-87 2007). The samples were placed in the combustion vessel under high pressure oxygen environment (450 psi). The combustion vessel is surrounded by a known quantity of water. Heat absorbed by combustion vessel, calorimetric vessel and other parts of calorimeter is determined as water equivalent of calorimeter using a known weight pellet of benzoic acid. The instrument measures the gross calorific value based on the water equivalent of the calorimeter and an increase in temperature on sample ignition.

\subsection{Energetic assessment}

A triangular plot known as Tanner diagram is one of the applicable methods to make a rapid evaluation of various solid waste fractions for energy related operations (Komilis et al., 2014; Zhao et al., 2016). Conventionally it is used to test the self-sustained combustibility of the waste streams based on three criteria i-e; the moisture content of the sample ( $\mathrm{M} \%)$, ash content (A \%) and combustibles C\% (fixed carbon\% + volatile solids \%) making a sum of 1 or $100 \%$. The theory suggests that the waste is feasible for self-combustion if the $\mathrm{M} \%<50 \%, \mathrm{~A} \%<60 \%$ and $\mathrm{C} \%>25 \%$ (Montgomery, 2005; Tanner, 1965). A number of 
triangular graphs were constructed considering the same quality standards and compared to tanner diagram, hence in this study the practice is employed as a quick visual assessment tool to present the energetic feasibility of waste samples for their utilization as a fuel alone and the effects of its blending with different proportions of indigenous coal on energy performance for cocombustion in power plant and RDF plant operations.

\subsection{Economic assessment}

A simple economic assessment was carried out to illustrate the feasibility of existing indigenous coal (Khaushab and Chamalang coal) and biomass resources (sugar bagasse, rice husk and MSW organic waste) for their utilization as a fuel in power generation. The focus is on coal-only power generation compared with different ratios of studied coal types and organic fractions to determine the most economical co-combustion fuel proportions.

The economic assessment was carried out using a generalized mathematical equation; the equation represents the results considering different tested samples, their costs and calorific values. The running cost is mainly based on the price of fuel, the majority of the total cost of coal-only generation comes from purchasing of coal. Large quantities of organic waste and agricultural residues are produced in Pakistan and available at cheap prices. Other coal plant operation and maintenance costs (labor, environmental controls, etc.) are assumed constant with respect to co-combustion rate and are not included in the cost estimates for the purpose of comparing the cost of co-combustion vs. coal-only electricity generation. The calorific value of various tested samples is often a decisive parameter to determine the potential economics of different products or services. The costs of different fractions were summed up and associated variations in costs were calculated considering the ratios and calorific values of the studied samples. The economic assessments were carried out based on the costs and the amount of different fuels required to produce $1 \mathrm{kWh}$ of electricity in a coal fired power plant.

$\mathrm{PFE}=(\% \mathrm{C} . \mathrm{PC}+\% \mathrm{BF} . \mathrm{PBF}) *$ Amount of fuel

Amount of fuel $=\mathrm{RCV} /(\mathrm{SCV} *$ plant efficiency $)$

Here,

PFE = Price of fuel to produce $1 \mathrm{kWh}$ of electricity in a coal fired plant

$\% \mathrm{C}=$ Percentage of Coal in the sample

$\% \mathrm{BF}=$ Percentage of Biomass waste fraction in the sample

$\mathrm{PC}=$ Price of used coal

$\mathrm{PBF}=$ Price of used Biomass waste fraction

$\mathrm{RCV}=$ Required calorific value to produce $1 \mathrm{kWh}$ electricity

$\mathrm{SCV}=$ Calorific value of the sample

The energy conversion is determined by the efficiency of the power plant boiler and combustion process which is typically between $70-80 \%$ depending on boiler type and its maintenance. Second stage is dependent on vapor cycle efficiency, modern coal fired power plants usually boast efficiencies that vary from $32-40 \%$. In this case we assume the conversion efficiency at $75 \%$ and the vapour cycle efficiency as 36\% (IEA, 2010), the overall efficiency of the power plant turns out to be $27 \%$.

Table 1. Results of proximate analysis, GCV and CHNS content of coal samples, biomass and organic fractions of MSW

\begin{tabular}{|c|c|c|c|c|c|}
\hline \multirow{2}{*}{ Constituent } & \multicolumn{2}{|c|}{ Coal Sample } & \multicolumn{3}{|c|}{ Biomass Sample } \\
\hline & Chamalang & Khushab & Sugarcane Bagasse & Rice Husk & Organic MSW \\
\hline Moisture (\%) & 3.07 & 2.84 & 3.97 & 4.4 & 43.14 \\
\hline Volatile Matter (\%) & 35.25 & 46.77 & 78.60 & 65.34 & 45.19 \\
\hline Ash (\%) & 25.99 & 9.6 & 4.3 & 16.2 & 4.72 \\
\hline Fixed Carbon (\%) & 35.69 & 40.79 & 13.1 & 14.06 & 6.94 \\
\hline Calorific Value (Kcal/Kg) & 5460 & 6145 & 2995 & 3518 & 3285 \\
\hline \multicolumn{6}{|c|}{ CHNSO Content } \\
\hline Carbon(\%) & 68.8 & 80.3 & 41.8 & 38.5 & 40.3 \\
\hline Hydrogen (\%) & 4.2 & 4.5 & 5.35 & 5.31 & 6.1 \\
\hline Nitrogen (\%) & 0.6 & 0.5 & 0.37 & 0.28 & 3.3 \\
\hline Sulphur (\%) & 6.6 & 3.9 & 0.187 & 0.34 & 0.45 \\
\hline Oxygen (\%) & 26.4 & 14.7 & 52.48 & 55.91 & 50.3 \\
\hline
\end{tabular}

\section{Results and discussion}

The physical characteristics and gross calorific value of two indigenous coal samples from two different coalfields in Pakistan and three abundantly available biomass waste fractions (rice husk, sugarcane bagasse and organic fraction of MSW) were studied inferring the results shown in Table 1. The combustion behavior of biomass fractions in general is different than coal. The volatile matter and fixed carbon both contain energy and that is released on combustion. The high volatility reflects that less amount of fixed carbon is left as residual. The combustion of coal is based on the burning of fixed carbon content while in biomass, it's predominantly the volatile content that ignites (Gil et al., 2010). Ash content is the amount of residue that would be left behind upon combustion of tested samples.

The physical characteristics and calorific value of different coal samples vary with the age, ranking and location of the coal mines. Khaushab coal is from Salt Range Punjab, 
while Chamalang coal is from Chamalang Balochistan. Among two coal samples the combustion efficacy of Khaushab coal is better than Chamalang coal owing to low moisture content, high volatility, less ash and high calorific value, while the sulphur content was also found to be less. For Khaushab coal the amount of fixed carbon was found to be slightly above $40 \%$. The sulphur content was found to be about $3.9 \%$ (a value $>3 \%$ is an indication of high sulphur coal). The calorific value of coal samples alone has been found to be $6145 \mathrm{kcal} / \mathrm{kg}$. While for chamalang coal the amount of fixed carbon is about $33 \%$, the coal samples received have high sulphur and ash content of $6.6 \%$ and $25.99 \%$ respectively. Whereas the heating values of the coal samples were found to be $5460 \mathrm{kcal} / \mathrm{kg}$ and could be ranked as sub bituminous to bituminous coal (Asghar et al., 2015). In evaluating the results, it was observed that the combustion behavior of different biomass fractions is different than coal with high moisture content and volatility while the fixed carbon content and ashes are lower accordingly. The studied physical characteristics also vary among various biomass fractions (rice husk, sugarcane bagasse and organic fraction of solid waste). In this respect, rice husk and sugarcane bagasse have much lower moisture content than organic fraction of solid waste while their volatility and fixed carbon content are comparatively higher. On the other hand, the sugarcane bagasse samples, and organic waste samples were found similar in ash content ( $4 \%$ to $5 \%$ ) due to the high volatility of the former and high moisture content of the later. The rice husk showed most favorable characteristics as a fuel with higher calorific value due to the oil content of rice husk, while sugarcane bagasse samples exhibited lower calorific value among three. The waste components generally had high carbon content and moderate hydrogen content, indicating a good energy potential, while the sulphur content was also observed to be very low as compared to studied coal samples. The results are, however, dependent on the sources of the samples and the way samples are processed in these facilities. The municipal solid waste samples were taken directly from residential areas, while the rice husk and sugarcane samples were taken from respective industries where some drying process has already taken place.

\subsection{Projected energetic validation}

The coal and biomass waste fractions blends were prepared with the addition of $20 \%, 40 \%, 60 \%$ and $80 \%$ biomass fractions in coal on a weight basis (with 80 mesh size). The studied physical characteristics of a series of blends are presented in an alternative graphical way (ternary plot) to illustrate the energetic feasibility and cocombustion efficiency of various coal and biomass samples while considering the effect of blending. These graphs are based on the available moisture content, combustible and ash content data; since, these characteristics could offer a good indication of the combustibility of tested samples. Different points represent the experimental location of various samples. Here, 100:0 represents results for $100 \%$ coal, $80: 20$ depicts $80 \%$ coal and $20 \%$ biomass content, $60: 40$ is an indication of blend with $60 \%$ coal and $40 \%$ biomass, $20: 80$ shows $20 \%$ coal and $80 \%$ biomass content and $0: 100$ is a $100 \%$ biomass sample.

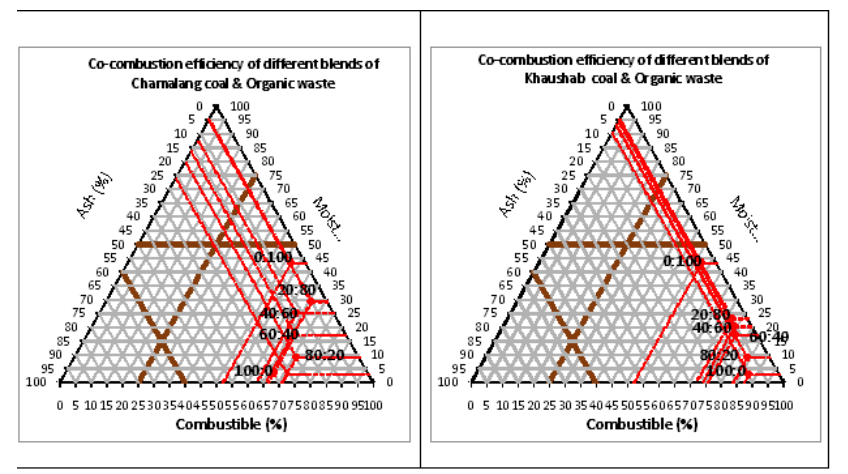

Figure 1. Tanner triangle depicting combustion efficiency of different blends of Chamalang and Khaushab coal with organic waste in various ratios.

Organic MSW contain heterogeneous material with much higher moisture content and lower devolatization temperature than coal due to the presence of complex but easily decomposed components like cellulose and PVC (Gil et al., 2010). The studied samples of coal and the organic fraction of municipal solid waste are in agreement with these findings. The graphical representation of organic MSW and their various blends with Chamalang coal indicated a significant increase in the amount of moisture as the proportion of organic fraction increased from 0 to $100 \%$ from as low as $3.07 \%$ to as high as $43.14 \%$ with a standard deviation of 14.52. On the other hand, the amount of combustible and ash content decreased correspondingly from $70.97 \%$ to $52.1 \%$ and $26 \%$ to $4.7 \%$ with a standard deviation of 6.98 and 9.42 respectively. Organic waste co-combustion with Khaushab coal demonstrated a sharp increase in the moisture content from $2.8 \%$ to $43 \%$ with a standard deviation of 13.9 , while the amount of combustible was observed to have a vertical decrease from $87.5 \%$ to $52 \%$. The ash content showed a relatively less decline from $4.7 \%$ to $9.6 \%$ with a standard deviation of 1.83 along with increasing replacement of coal with biomass. The samples with the highest calorific value are positioned at the bottom left corner of the graph while a decrease in calorific value is observed at upward locations, the decrease can be associated with the increase in the amount of biomass.

The physical characteristics of Chamalang coal, Khaushab coal, sugarcane baggase and their various blends are graphically depicted here. The sugarcane baggasse samples were observed to have low moisture content and their blending with Chamalang coal specified slight decrease in moisture content from $3.97 \%$ to $3.07 \%$ with a standard deviation of 0.40 only. Sugarcane baggase cocombustion with Khaushab coal demonstrated the moisture content increase from $2.8 \%$ to $43 \%$ with a standard deviation of 13.9. The studied samples were mainly composed of combustible matter that varied from $91.6 \%$ to $66.8 \%$ for different blends of Chamalang coal and $91.7 \%$ to $87.6 \%$ for various Khaushab coal blends. Among the tested samples the $100 \%$ coal samples had the 
lowest volatile contents and high fixed carbon content which decreases correspondingly with increasing biomass content due to the high volatility of sugar cane bagasse. A decrease in ash content from $30.1 \%$ to $4.3 \%$ and from $9.6 \%$ to $4.3 \%$ with a standard deviation of 9.7 and 2.1 was observed for Chamalang and Khaushab coal blends respectively.

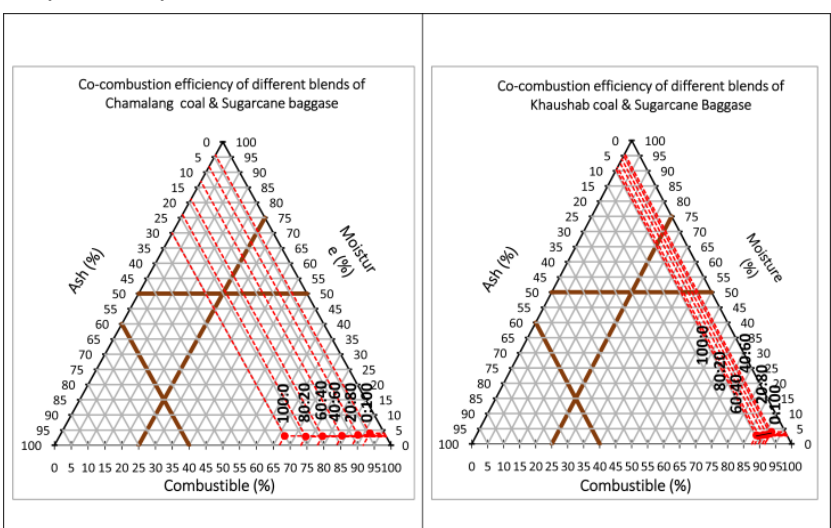

Figure 2. Tanner triangle depicting combustion efficiency of different blends of Chamalang and Khaushab coal with sugarcane baggase in various ratios.

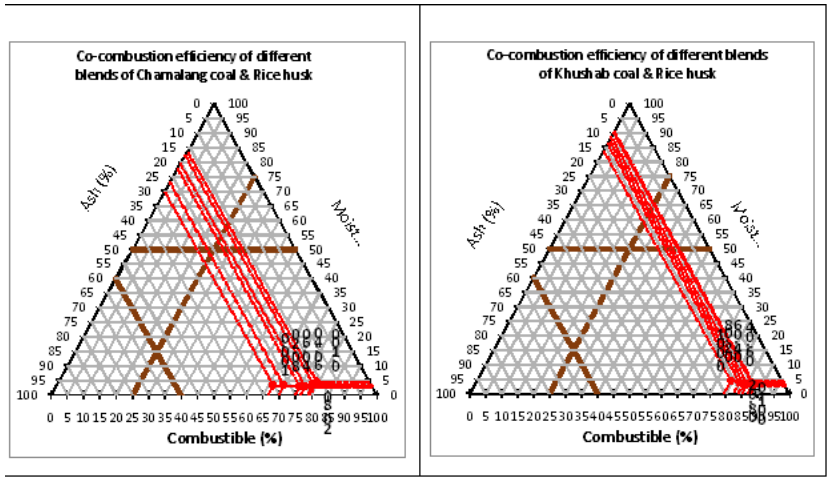

Figure 3. Tanner triangle depicting combustion efficiency of different blends of Chamalang and Khaushab coal with rice husk in various ratios.

The experiments for various samples of Chamalang coal with rice husk exhibited slight increase in the amount of moisture as proportion of rice husk increased from 0 to $100 \%$ from as low as $2.77 \%$ to as high as $4.4 \%$ with a standard deviation of 0.613 . The amount of combustible also increases from $66.8 \%$ to $79.4 \%$, while the ash content decreased correspondingly from $30.1 \%$ to $16.2 \%$ with a standard deviation of 5.38 . The co-combustion behavior of Khaushab coal blends for $20 \%, 40 \%, 60 \%, 80 \%$ blending ratios with rice husk follow more or less similar trend i-e; they show less variation in moisture content from $4.4 \%$ to $2.8 \%$ with a standard deviation of 0.577 and a relatively less significant decrease in combustible content from $87.5 \%$ to $79.4 \%$ with a standard deviation of 3.04 that leads to relatively high ash content that increases from $9.6 \%$ to $16.2 \%$ with a standard deviation of $2.47 \%$ along increasing biomass blending ratios.

The overall results suggest that all the blending experiment show some comprehensible results where the moisture contents and combustibles increase, and the amount of ash contents decrease with increased biomass ratio. A comparison of biomass blends with both coal types exhibited a more notable variation in studied parameters for Chamalang coal as compared to Khaushab coal as the biomass fraction increases in the mixtures. The result evaluation suggests that the average moisture content of biomass waste samples is almost $17.7 \%$, while the average moisture content of two studied coal samples in $2.9 \%$. The moisture content increases with increased biomass fraction in the blends. The average moisture content increase in the blends of Chamalang coal and biomass waste from as low as 3.07 to as high as 43.14 . While for Khaushab coal the blending with biomass waste increases the moisture content to $6.6 \%$ on average. The biomass waste fraction has high volatility and low fixed carbon content, the average volatile matter of biomass fractions sampled is $63.04 \%$, which is much higher than the volatile matter released from coal combustion. The average rise in the volatility of Chamalang coal and biomass blends is 18.57, while for Khaushab coal and biomass blends volatility increases to an average of $26.1 \%$. The ash content, in general is found to decrease with increased biomass and increased volatility. The average ash content of biomass fraction is $8.4 \%$ and upon blending the coal ash content can be reduced up to $9.90 \%$. The ash content, however, can be affected by the mud and grit present in the samples.

The tanner diagram visualization for the assessment of proposed blends suggest that all the trial samples lie within the given limits for three discussed parameters i-e; $M<50 \%, A<60 \%$, and $C>25 \%$ and can sustain selfcombustion without any auxiliary fuel. Theoretically, the results propose that the tested biomass waste samples alone and their various blends are appropriate for utilization in energy related operation. Calorific value is an important parameter when comparing different fuels relative to energy production. As anticipated, the highest GCV of $6145 \mathrm{Kcal} / \mathrm{kg}$ for Khaushab coal and $5460 \mathrm{Kcal} / \mathrm{kg}$ for Chamalang coal were observed to decrease with an increase in blending proportion of organic waste. The decrease in calorific value of tested samples is attributed to higher moisture content, increased volatility and decreased fixed carbon and ash content.

\subsection{Economic assessment}

The project type, size and technology choice are dependent on the cost and efficiency of various technologies as well as the local requirements of electricity. However, the availability and cost of required fuel also play an important role in regulating the financial matter. The capital cost of a power plant mainly includes its land and construction cost. A study suggested that an estimated cost for coal plant construction is between $\$ 1,500$ and $3,500 / \mathrm{kW}$, (Schlissel et al., 2008) while retrofitting coal plants for co-firing requires a lesser cost of between $\$ 430$ and $\$ 500 / \mathrm{kW}$ for co-feed plant and USD $\$ 760-900 / \mathrm{Kw}$ for separate feed plants (ETSAP, 2013). Considering the calorific values and associated prices of tested samples, the results present the biomass and coal co-combustion samples that can provide the greatest savings from reduced fuel cost compared to coal-only using existing coal plants for the production of $1 \mathrm{kWh}$ of 
electricity. The market price of khaushab and chamalang coal are $24 \mathrm{Rs} . / \mathrm{kg}$ and $22 \mathrm{Rs} / \mathrm{kg}$ respectively. The market price of rice husk is approximately $8 \mathrm{Rs} . / \mathrm{kg}$ because of its demand in various other operations. Sugarcane bagasse is

Table 2. Gross Calorific values (Kcal/ Kg) for different coal and biomass waste samples and their various blending ratios

\begin{tabular}{|c|c|c|c|c|c|c|}
\hline \multirow{2}{*}{ Constituents } & \multicolumn{6}{|c|}{ Gross Calorific values (Kcal/Kg) for different coal and biomass blending ratios } \\
\hline & 100:0 & $80: 20$ & $60: 40$ & 40:60 & 20:80 & 0:100 \\
\hline Khaushab coal + OMSW & 6145 & 5371 & 4822 & 4263 & 3709 & 3285 \\
\hline Khaushab coal + Rice Husk & 6145 & 5424 & 4907 & 4410 & 3903 & 3518 \\
\hline Khaushab coal+ Sugarcane bagasse & 6145 & 5329 & 4716 & 4100 & 3484 & 2995 \\
\hline Chamalang coal + OMSW & 5460 & 4840 & 4425 & 4010 & 3590 & 3285 \\
\hline Chamalang coal + Rice Husk & 5460 & 4875 & 4499 & 4123 & 3745 & 3518 \\
\hline Chamalang coal + Sugarcane bagasse & 5460 & 4766 & 4299 & 3813 & 3334 & 2995 \\
\hline
\end{tabular}

Table 3. Approximate Fuel Prices (Pak Rs.) for production of $1 \mathrm{kWh}$ of electricity utilizing different coal and biomass blending ratios

\begin{tabular}{|c|c|c|c|c|c|c|}
\hline Constituents & \multicolumn{7}{|l}{ Fuel Prices (Pak Rs.) for production of 1kWh of electricity utilizing different coal and biomass } \\
blending ratios
\end{tabular}

As the table suggests co-firing results in a total cost reduction, compared to using coal only. The savings are related to lower biomass charges. The comparison of total cost of coal firing vs Co-combustion proposes that production cost of electricity from a power plant producing $1 \mathrm{kWh}$ of electricity using 100\% Khaushab and Chamalang coal is approximately 12 to 13 Rs. respectively which can be reduced to less than 1 Rs. due to cheap organic municipal waste costs and vice versa.

\section{Conclusion}

Co-combustion is being claimed to process a wide variety of materials into fuel with reasonable fuel efficiency. The prospect of abundantly available biomass waste fractions as a fuel alone and their co-combustion with two different indigenous coal varieties has been emphasized in the study. The combustion characteristics of studied samples inferred that both coal and biomass fuels alone and their co-combustion in various proportions can be feasible for energy exploitation. Within the assortment of conducted trials, different blended ratios of Khaushab coal with Rice husk evidenced to be the optimum options of fuel for energy production. These fuel blends proved to be most favorable when assessed using tanner diagram owing to their low moisture content and high volatility. Cocombustion of biomass fuels with coal can also reduce NOx and SOx levels from coal-only fired power plants as biomass is a carbon neutral fuel and contains less sulphur. Additionally, co-combustion can lead to many economic benefits including low capital investment, reduction in fuel costs, and prompt availability of resources.

Co-combustion technology is gaining popularity worldwide and progressed from lab-scale investigations to long-term demonstrations. The need is to develop such systems country-wide incrementally from small to grand scale with periodic evaluation for technicalities and effectiveness. The heterogeneity of used fractions, optimum blending mechanism, the preferred particle size of the available blend, and feeding mechanism are the subjects that require further expertise and supportive studies. The overall result of the research inferred that both coal and biomass fuels alone and their co-firing can sustain self-combustion. The envisioned benefit can subsequently arrange for finding area-based solutions related to massive amounts of produced organic waste and endorse in finding sustainable solutions for increasing energy demands within the country.

\section{References}

Abbasi T., Tauseef S.M., Abbasi S.A. (2012), Anaerobic digestion for global warming control and energy generation-An overview, Renewable and Sustainable Energy Reviews, 16, 3228-3242.

Abila N. (2014), Managing municipal wastes for energy generation in Nigeria, Renewable and Sustainable Energy Reviews, 37,182-190.

Amjid S.S., Bilal M.Q., Nazir M.S., Hussain A. (2011), Biogas, renewable energy resource for Pakistan, Renewable and Sustainable Energy Reviews, 15(6), 2833-2837.

Asghar H.M.A., Mirza M.S., Mehmood K., Sattar H., Hussain S.N. (2015), Beneficiatipon of Chamalang Coal by Froath Floatation. In 2015 International Conference on Advances in Environment Research.

Asian Development Bank [ADB]. (2008), Islamic Republic of Pakistan Country Environment Analysis.

Asif M. (2009), Sustainable energy options for Pakistan, Renewable and Sustainable Energy Reviews. 13, 903-909.

ASTM D197-87 (2007), Standard Test Method for Sampling and Fineness Test of Pulverized Coal, ASTM International, West Conshohocken.

ASTM E711-87 (2007), Standard Test Method for Gross Calorific Value of Refused Derived Fuel by the Bomb Calorimeter, ASTM International, West Conshohocken. 
Brunner P.H. and Rechberger H. (2015), Waste to energy - key element for sustainable waste management, Waste Management, 37, 3-12.

Del-Borghi A., Gallo M., Del-Borghi M. (2009), A survey of life cycle approaches in waste management, The International Journal of Life Cycle Assessment, 14(7), 597-610.

Dong J., Chi Y., Zou D., Fu C., Huang Q., Ni M. (2014), Energyenvironment-economy assessment of waste management systems from a life cycle perspective: Model development and case study, Applied Energy, 114, 400-408.

Eriksson O., Bisaillon M., Haraldsson M., Sundberg J. (2014), Integrated waste management as a mean to promote renewable energy, Renewable Energy, 61, 38-42.

ETSAP (2013), Energy Technology System Analysis Programme, International Renewable Energy Agency.

Fantin V., Giuliano A., Manfredi M., Ottaviano G., Stefanova M., Masoni P. (2015), Environmental assessment of electricity generation from an Italian anaerobic digestion plant, Biomass and Bioenergy, 83, 422-435.

Fruergaard T. and Astrup T. (2011), Optimal utilization of wasteto-energy in an LCA perspective. Waste Management, 31, 572-582.

Gil M.V., Oulego P., Casal M., Pevida C., Pis J.J., Rubiera F. (2010), Mechanical Durability and Combustion Characteristics of pellets from Biomass Blends, Bioresource Technology, 101, 8859-8867.

GOP (2018), Pakistan Economic Survey 2017-18.

Hoi-Seong J., Kwang-Yim K. (2007), KOICA-WorldBank Joint Study on Solid Waste Management in Punjab, Pakistan.

IEA (2010), Power generation from coal.

IEA (2019), World Energy Outlook.

Kojakovic A. and Maltsoglou I. (2014), Biomass Resource Mapping in Pakistan: Scoping Phase Peport. Food \& Agriculture Organization of the United Nations,

Komilis D., Kissas K., Symeonidis A. (2014), Effect of organic matter and moisture on the calorific value of solid wastes: An update of the Tanner diagram, Waste Management, 34, 249-255.

Kondusamy D. and Kalamdhad A.S. (2014), Pre-treatment and anaerobic digestion of food waste for high-rate methane production - A review, Journal of Environmental Chemical Engineering, 2:1821-1830.

Kothari R., Pandey A.K., Kumar S., Tyagi V.V., Tyagi S.K. (2014), Different aspects of dry anaerobic digestion for bioenergy: An overview Renewable and Sustainable Energy Reviews, 39, 174-195.

Kumar A., Jones D.D., Hanna M.A. (2009), Thermochemical biomass gasification: a review of the current status of the technology, Energies, 2(3), 556-581.

Li S., Xu S., Liu S., Yang C., Lu Q. (2004), Fast pyrolysis of biomass in free-fall reactor for hydrogen-rich gas, Fuel Processing Technology, 85, 1201-1211.

Malkani M.S. (2012) A review of coal and water resources of Pakistan Science, Technology and Development, 31, 202-218

Montgomery D. (2005), Design and Analysis of Experiments. sixth edition edn. J. Wiley \& Sons Inc., USA.,

Mussatto S.I., Dragone G., Guimarães P.M., Silva J.P.A., Carneiro L.M., Roberto I.C., et al. (2010), Technological trends, global market, and challenges of bio-ethanol production, Biotechnology advances, 28(6), 817-830.
Naqvi S.R., Jamshaid S., Naqvi M., Farooq W., Niazi M.B.K., Aman Z., et al. (2018), Potential of biomass for bioenergy in Pakistan based on present case and future perspectives, Renewable and Sustainable Energy Reviews, 81, 1247-1258.

Ngoc U.N. and Schnitzer H. (2009), Sustainable solutions for solid waste management in Southeast Asian countries, Waste management, 29(6), 1982-1995.

Rauf O., Wang S., Yuan P., Tan J. (2015), An overview of energy status and development in Pakistan, Renewable and Sustainable Energy Reviews, 48, 892-931.

Safeer R. and Fatima N. (2019), Energy Scenario and Diversity in Pakistan: An Energy Security Perspective Advances in Energy and Power, 6, 1-11.

Sahu S.G., Chakraborty N., Sarkar P. (2014), Coal-biomass cocombustion: An overview, Renewable and Sustainable Energy Reviews, 39, 575-586.

Schiffer H.W. (2016), World Energy Resources, World Energy Council,

Schlissel D., Smith A., Wilson R. (2008), Coal Fired Power Plant Construction Costs. Synapse Energy Economics, Inc., Cambridge.

Seadon J.K. (2006), Integrated waste management-Looking beyond the solid waste horizon, Waste management, 26(12), 1327-1336.

Sebi C. (2019), Explaining the increase in coal consumption worldwide, Australia.

Tanner V.R. (1965), Die Entwicklung der Von-RollMüllverbrennungsanlagen (The development of the Von-Roll incinerators) Schweizerische Bauzeitung (in German), 83, 251-260.

Varadhan S. (2019), India expects caol-fired power capacity to grow $22 \%$ in 3 years, Thomson Reuters.

Williams A., Pourkashanian M., Jones J.M. (2001), Combustion of pulverised coal and biomass, Progress in energy and combustion science, 27(6), 587-610.

World Bank. Pakistan development update Washington, DC. (2015) CWorld Bank.

Yasmeen F. and Sharif M. (2014), Forecasting electricity consumption for Pakistan. International Journal of Emerging Technology and Advanced Engineering, 4(4), 496-503.

Zhao L., Giannis A., Lam W-Y., Lin S-X., Yin K., Yuan G-A., Wang JY. (2016), Characterization of Singapore RDF resources and analysis of their heating value, Sustainable Environment Research, 26:51-54. 